\title{
A Brainer on Neurotoxicity
}

\author{
Ellen Fritsche ${ }^{1,2 *}$ and Helena Therese Hogberg ${ }^{3 *}$ \\ ${ }^{1}$ IUF-Leibniz Research Institute for Environmental Medicine, Düsseldorf, Germany, ${ }^{2}$ Medical Faculty, \\ Heinrich-Heine-University, Düsseldorf, Germany, ${ }^{3}$ Center for Alternatives to Animal Testing (CAAT) at the Johns Hopkins \\ Bloomberg School of Public Health, Baltimore, MD, United States
}

Keywords: neurotoxicity, DNT, human relevance, developmental neurotoxicity, susceptible life stages

\section{OPEN ACCESS}

Edited by:

Timothy J. Shafer,

United States Environmental

Protection Agency (EPA),

United States

Reviewed by:

David M. Reif,

North Carolina State University, United States

Anke Marije Tukker,

Utrecht University, Netherlands

*Correspondence:

Ellen Fritsche

ellen.fritsche@iuf-duesseldorf.de

Helena Therese Hogberg

hhogber2@jhu.edu

Specialty section:

This article was submitted to Neurotoxicology,

a section of the journal

Frontiers in Toxicology

Received: 19 May 2020

Accepted: 11 June 2020

Published: 30 June 2020

Citation:

Fritsche E and Hogberg HT (2020) A

Brainer on Neurotoxicity.

Front. Toxicol. 2:3.

doi: 10.3389/ftox.2020.00003
We talk about adult neurotoxicity when exposure to natural or manmade toxic substances, interferes with normal nervous system activity and function. Neurotoxicity might disrupt or even kill neurons or the surrounding glia cells by interfering with neural function. Special attention must be given to susceptible subgroups such as, the very young (developmental neurotoxicity - DNT) and the aging population, as neurotoxicity's mode-of-action (MoA) or sensitivity differs for them vs. healthy adults. So far, neurotoxicity has been evaluated using animal models, rodent primary, or tumor in vitro cultures, and human epidemiology.

The field of neurotoxicology has benefitted tremendously from the field of drug development for nervous system disorders. High attrition rates, (at least 50\%) in general (Smietana et al., 2016) and for central nervous system (CNS) drugs specifically (Arrowsmith and Miller, 2013; DiMasi, 2014; Harrison, 2016; Mohs and Greig, 2017), were attributed to insufficient human predictability of nonclinical biological data, i.e., efficacy and safety issues (Bailey et al., 2014; DiMasi, 2014; Harrison, 2016; Cavero et al., 2019). For CNS drug development, transgenic animals modeling human disease are widely used. The especially high failure rate of CNS drug developments is ascribed amongst others to the complexity of human CNS diseases that often involve multiple molecular targets. Furthermore, experimental animal disease models have relatively low predictive validity, and there is lack of established clinical biomarkers and proof-of-concept models for these diseases (Kola and Landis, 2004; Palmer and Stephenson, 2005). The failure rate in clinical trials is especially high for neurodegenerative disorders such as Alzheimer disease where $99.6 \%$ of drugs do not make it to the market (Pistollato et al., 2016; Mohs and Greig, 2017). Including human-relevant pharmacokinetics and bioavailability early into the drug development phase already reduced drug failure rates (Kola and Landis, 2004). Hence, improvement of the pharmaco-/toxicodynamics of models in health and disease for predicting not only drug effects but also the neurotoxicity of environmental chemicals, particulate matter, or other noxae will aid the development of better human prediction (Leist and Hartung, 2013; Cavero et al., 2019).

It was in the year 1993 when the use of stem cells for toxicological research was first proposed. It took 10 more years to first involve mouse embryonic stem cells in neurotoxicity evaluation. In 2006, human-induced pluripotent stem cells (hiPSC) entered the field and were first applied for neurotoxicity evaluation in 2016 (Barenys and Fritsche, 2018). For over three decades, almost, toxicity in general as well as neurotoxicity evaluation have seen dramatic changes. A future was envisioned in which toxicology relied primarily on high-throughput in vitro assays and computational models based on human biology to evaluate potential adverse effects of chemical exposures in a regulatory context (NRC, 2007). Moreover, the value of exposure science and epidemiology was strongly recognized for achieving human-relevant risk assessment in the future (NRC, 2012, 2017). In the area of neurotoxicity, these novel concepts have specifically and systematically been taken up for DNT. A global scientific network has been aimed at setting up a DNT in vitro testing battery consisting of primarily human stem/progenitor cell-based assays as well as zebrafish - as an alternative model organism-with the ultimate goal of application for 
regulatory purposes (Lein et al., 2005; Bal-Price et al., 2015, 2018; Fritsche et al., 2017, 2018; OECD, 2020). In vitro methodologies for studying acute neurotoxicity have also seen rapid advancement. Reproducible production of electrically active human neurons in cultures has been achieved, and the transition from $2 \mathrm{D}$ to $3 \mathrm{D}$ methods allows us to obtain complex models suitable for investigating neurotoxicity or brainrelated diseases also with patient-derived cells (Grainger et al., 2018; Yla-Outinen et al., 2019). Thus, human iPSC-derived cells offer a platform with the unique advantage of almost unlimited availability and reproducing the "human context" in vitro by preserving the genetic and molecular phenotype of their donors. Despite this, stem cells differentiated into neurons and astroglia, which have been the most common cell types used for neurotoxicity testing so far, do not solely represent the wholeness of a brain. Novel strategies, for example, implementing oligodendrocytes (Pamies et al., 2017, 2018), microglia (Abreu et al., 2018), region-specific astrocytes (de Majo et al., 2020), and vasculature (Worsdorfer et al., 2020) in standard neurotoxicity test methods, need more attention. In addition, while brain organoids offer much promise, there is a need to improve both the reproducibility and throughput of these models so that they can reach their full potential for neurotoxicity and DNT testing (Sivitilli et al., 2020).

\section{REFERENCES}

Abreu, C. M., Gama, L., Krasemann, S., Chesnut, M., Odwin-Dacosta, S., Hogberg, H. T., et al. (2018). Microglia increase inflammatory responses in iPSC-derived human BrainSpheres. Front. Microbiol. 9:2766. doi: 10.3389/fmicb.2018.02766

Arrowsmith, J., and Miller, P. (2013). Trial watch: phase II and phase III attrition rates 2011-2012. Nat. Rev. Drug Discov. 12:569. doi: 10.1038/nrd4090

Bailey, J., Thew, M., and Balls, M. (2014). An analysis of the use of animal models in predicting human toxicology and drug safety. Altern. Lab. Anim. 42, 181-199. doi: 10.1177/026119291404200306

Bal-Price, A., Crofton, K. M., Leist, M., Allen, S., Arand, M., Buetler, T., et al. (2015). International STakeholder NETwork (ISTNET): creating a developmental neurotoxicity (DNT) testing road map for regulatory purposes. Arch. Toxicol. 89, 269-287. doi: 10.1007/s00204-015-1464-2

Bal-Price, A., Hogberg, H. T., Crofton, K. M., Daneshian, M., FitzGerald, R. E., Fritsche, E., et al. (2018). Recommendation on test readiness criteria for new approach methods in toxicology: exemplified for developmental neurotoxicity. ALTEX 35, 306-352. doi: 10.14573/altex.1712081

Barenys, M., and Fritsche, E. (2018). A historical perspective on the use of stem/progenitor cell-based in vitro methods for neurodevelopmental toxicity testing. Toxicol. Sci. 165, 10-13. doi: 10.1093/toxsci/kfy 170

Cavero, I., Guillon, J. M., and Holzgrefe, H. H. (2019). Human organotypic bioconstructs from organ-on-chip devices for human-predictive biological insights on drug candidates. Expert Opin. Drug Saf. 18, 651-677. doi: 10.1080/14740338.2019.1634689

de Majo, M., Koontz, M., Rowitch, D., and Ullian, E. M. (2020). An update on human astrocytes and their role in development and disease. Glia 68, 685-704. doi: 10.1002/glia.23771

DiMasi, J. A. (2014). CNS Drugs Take Longer to Develop and Have Lower Success Rates Than Other Drugs. Tufts Center for the Study of Drug Development. Available online at: http://csdd.tufts.edu/.

Fritsche, E., Barenys, M., Klose, J., Masjosthusmann, S., Nimtz, L., Schmuck, M., et al. (2018). Current availability of stem cell-based in vitro methods for developmental neurotoxicity (DNT) Testing. Toxicol. Sci. 165, 21-30. doi: $10.1093 /$ toxsci/kfy178
The Specialty Section Neurotoxicology in the journal Frontiers in Toxicology will focus on 'Human Relevance' as an overarching theme. Papers are encouraged to deal with cutting-edge research in in vivo, in vitro, in silico, and in epidemiological approaches for neurotoxicity evaluation of all life stages. Primary research as well as review articles of all areas touching on neurotoxicological research are welcome. The human relevance of these findings needs to be discussed irrespective of the methods applied. Articles will target a broad audience including academic and clinical researchers as well as toxicologist from industry and regulatory agencies. Thus, the Specialty Section Neurotoxicology of Frontiers in Toxicology aims at generating a community for neurotoxicologists worldwide.

\section{AUTHOR CONTRIBUTIONS}

$\mathrm{EF}$ and $\mathrm{HH}$ wrote the manuscript. All authors contributed to the article and approved the submitted version.

\section{FUNDING}

This work (EF) was supported by the project CERST (Center for Alternatives to Animal Testing) of the Ministry for culture and science (MKW) of the State of North-Rhine Westphalia, Germany [file number 233-1.08.03.03-121972].

Fritsche, E., Crofton, K. M., Hernandez, A. F., Hougaard Bennekou, S., Leist, M., Bal-Price, A., et al. (2017). OECD/EFSA workshop on developmental neurotoxicity (DNT): the use of non-animal test methods for regulatory purposes. Altex 34, 311-315. doi: 10.14573/altex.1701171

Grainger, A. I., King, M. C., Nagel, D. A., Parri, H. R., Coleman, M. D., and Hill, E. J. (2018). In vitro models for seizure-liability testing using induced pluripotent stem cells. Front. Neurosci. 12:590. doi: 10.3389/fnins.2018. 00590

Harrison, R. K. (2016). Phase II and phase III failures: 2013-2015. Nat. Rev. Drug Discov. 15, 817-818. doi: 10.1038/nrd.2016.184

Kola, I., and Landis, J. (2004). Can the pharmaceutical industry reduce attrition rates? Nat. Rev. Drug Discov. 3, 711-715. doi: 10.1038/nrd1470

Lein, P., Silbergeld, E., Locke, P., and Goldberg, A. M. (2005). In vitro and other alternative approaches to developmental neurotoxicity testing (DNT). Environ. Toxicol. Pharmacol. 19, 735-744. doi: 10.1016/j.etap.2004.12.035

Leist, M., and Hartung, T. (2013). Inflammatory findings on species extrapolations: humans are definitely no $70-\mathrm{kg}$ mice. Arch. Toxicol. 87, 563-567. doi: 10.1007/s00204-013-1038-0

Mohs, R. C., and Greig, N. H. (2017). Drug discovery and development: Role of basic biological research. Alzheimers Dement 3, 651-657. doi: $10.1016 /$ j.trci.2017.10.005

NRC (2007). National Research Council: Toxicity Testing in the 21st Century a Vision and a Strategy. Washington, DC: National Academy Press.

NRC (2012). National Research Council: Exposure Science in the 21st Century A Vision and $a$ Strategy. Washington, DC: National Research Council

NRC (2017). National Research Council: Using 21st Century Science to Improve Risk-Related Evaluations. Washington, DC: National Research Council.

OECD (2020). Report of the OECD/EFSA Workshop On Developmental Neurotoxicity (DNT): The Use of Non-Animal Test Methods for Regulatory Purposes. Series on Testing and Assessment, Organisation for Economic Co-operation and Development. Available online at: http://www. oecd.org/officialdocuments/publicdisplaydocumentpdf/?cote=ENV/JM/ MONO(2017)4anddocLanguage $=$ En, 2017.

Palmer, A. M., and Stephenson, F. A. (2005). CNS drug discovery: challenges and solutions. Drug News Perspect. 18, 51-57. 
Pamies, D., Barreras, P., Block, K., Makri, G., Kumar, A., Wiersma, D., et al. (2017). A human brain microphysiological system derived from induced pluripotent stem cells to study neurological diseases and toxicity. Altex 34, 362-376. doi: 10.14573/altex.1609122

Pamies, D., Block, K., Lau, P., Gribaldo, L., Pardo, C. A., Barreras, P., et al. (2018). Rotenone exerts developmental neurotoxicity in a human brain spheroid model. Toxicol. Appl. Pharmacol. 354, 101-114. doi: 10.1016/j.taap.2018.02.003

Pistollato, F., Ohayon, E. L., Lam, A., Langley, G. R., Novak, T. J., Pamies, D., et al. (2016). Alzheimer disease research in the 21st century: past and current failures, new perspectives and funding priorities. Oncotarget 7, 38999-39016. doi: 10.18632/oncotarget.9175

Sivitilli, A. A., Gosio, J. T., Ghoshal, B., Evstratova, A., Trcka, D., Ghiasi, P., et al. (2020). Robust production of uniform human cerebral organoids from pluripotent stem cells. Life Sci. Alliance 3:707. doi: 10.26508/lsa.2020 00707

Smietana, K., Siatkowski, M., and Moller, M. (2016). Trends in clinical success rates. Nat. Rev. Drug Discov. 15, 379-380. doi: 10.1038/nrd.2016.85
Worsdorfer, P., Takashi, I., Asahina, I., Sumita, Y., and Ergun, S. (2020). Do not keep it simple: recent advances in the generation of complex organoids. J. Neural Transm. doi: 10.1007/s00702-020-02198-8. [Epub ahead of print].

Yla-Outinen, L. J., Tanskanen, M. A., Kapucu, F. E., Hyysalo, A., J., et al. (2019). Advances in human stem cell-derived neuronal cell culturing and analysis. $A d v$. Neurobiol. 22, 299-329. doi: 10.1007/978-3-030-11135-9_13

Conflict of Interest: The authors declare that the research was conducted in the absence of any commercial or financial relationships that could be construed as a potential conflict of interest.

Copyright (c) 2020 Fritsche and Hogberg. This is an open-access article distributed under the terms of the Creative Commons Attribution License (CC BY). The use, distribution or reproduction in other forums is permitted, provided the original author(s) and the copyright owner(s) are credited and that the original publication in this journal is cited, in accordance with accepted academic practice. No use, distribution or reproduction is permitted which does not comply with these terms. 